\title{
Farewell to JEPS!
}

\section{Rebecca B. Morton and Joshua A. Tucker}

It is hard to believe that we have been at this for four years, but our term as editors is coming to a close. During this time, JEPS has gone from being little more than an idea in a few people's minds to a full fledged journal with robust submissions, excellent reviewers, and valuable published research from a wide range of scholars featuring all different types of experimental analyses employed in the study of politics. We are extremely excited by what JEPS has become, and we hope you share our enthusiasm!

Of course, none of this would have been possible without the assistance and hard work of many, many people. We would like to begin by thanking all of our Associate Editors, whose contribution to each and every issue of JEPS can not be overstated: Kevin Arceneaux, Eric Dickson, Jamie Druckman, Raymond Duch, Thad Dunning, Sean Gailmard, Donald Green, Leonie Huddy, Susan Hyde, Kosuke Imai, Kristin Kanthak, Bernhard Kittel, Esteban Klor, Neil Malhotra, Rose McDermott, Costas Panagopoulos, Jonathan Woon and Elizabeth Zechmeister. Gillian Greenough and Julia Chang from Cambridge University Press provided amazing encouragement, support, and assistance in getting a journal off the ground from scratch in the hands of two novice editors. We are also enormously indebted to our three graduate assistants at New York University, Sönke Ehret, Emine Deniz, and Marko Klašnja, without whom the day-to-day operation of the journal would have been so much less efficient! We were also very fortunate to work with three wonderful Chairs of the American Political Science Association's Section on Experimental Research: Jamie Druckman, Alan Gerber, and Lynn Vavreck. Finally, we wish to thank all of the authors who were generous enough to share their hard work with JEPS for consideration for publication, as well as all of the reviewers who helped us make the tough decisions regarding which of those high quality submissions would eventually be published in JEPS. We know that everyone's time is precious, and we appreciate that so many of you have chosen to share some of it with JEPS.

Finally, please join us in welcoming our new editor, Eric Dickson! It is always difficult to walk away from a job such as this, but we do so with confidence knowing the journal will be in Eric's excellent hands in the coming years! 
$* * * * *$

Note to readers: Our editors' notes in Vol. 1 were mistakenly included on the back cover of the printed version of the journal under the "Articles" heading, although they were not listed as such online. We hope it was clear from the content that neither of these were peer-reviewed articles, but just in case we wish to set the record straight, and to let readers know we have alerted our publisher to the issue and it should not occur in the future. 